\title{
Sobre as flautas sagradas xinguanas e a antropologização do mundo'
}

\section{Rafael José de Menezes Bastos}

Universidade Federal de Santa Catarina | Florianópolis, SC, Brasi

rafael.data.base@gmail.com

ORCID: https://orcid.org/0000-0002-1788-6050

RESUMO

Este artigo apresenta um estudo sobre as flautas sagradas nas terras baixas da América do Sul, tomadas as xinguanas como objeto central de atenção. Também, é uma abordagem do que chamo antropologização do mundo, ou seja, a inversão da hegemonia dos espíritos mamáe face aos humanos. O artigo explora a ideia de Pierre Clastres de "contra" que me levou a uma visão dos xinguanos como sociedades disciplinares, de acordo com Foucault, mas ainda assim em uma perspectiva contra a modernidade, a partir das considerações de Bruno Latour.
Dol

http://DX.DOI.ORG/

10.11606/1678-9857.

RA.2021.186653

1 | Este trabalho deve muito

a João Carlos Almeida,

doutorando do PPCAS/

UFSC realizando pesquisa

no Alto Xingu com foco nos

Yawalapití. Também, a Ayupú

Kamayurá, irmão júnior

e amigo há longo tempo

residente entre os Yawalapití,

embora seja Kamayurá.

Igualmente, a Acácio Tadeu

Piedade e Aristóteles Barcelos

Neto. Obrigado a Ordep José

Trindade Serra, pela versão ao

latim da dedicatória do artigo.

Também a Anthony Seeger,

Mark Munzel, Jean-Michel

Beaudet, Katia Kukawka e Luísa

Valentini pela ajuda. Muito

obrigado a Paola Gibram, Silvia

Beraldo, Deise Lucy Montardo,

Maria Eugenia Dominguez,

Kaio Domingues Hoffmann

e Izomar Lacerda - a este,

obrigado enfaticamente -

pela leitura e comentários a

uma versão prévia do texto.

Agradeço à finada colega

Maria Ignez Cruz Mello, a quem

dedico o texto com emoção.

Sou o único responsável por

ele. Pedro Cesarino foi em

relação a este escrito um editor

com rara sensibilidade.
PALAVRAS-CHAVE

Xinguanos,

flautas sagradas, interdição visual, antropologização do mundo,

Pierre Clastres

\section{About the xinguano sacred flutes and the antropologization of the world}

ABSTRACT This is a study about sacred flutes in lowland South America, taking the Xinguano as main subject matter. Also, it studies what I call antropologization of the world, or the inversion of the original hegemony of the mama'e spirits in relation to human beings. The article is an exploration departing from Clastres' idea of «against». The referred Clastres' idea has taken me to a vision of the

Xinguano as disciplinary societies, according to Foucault, but against modernity according to Latour's formulation of modernity.

KEYWORDS

Xinguano, sacred flutes visual interdiction anthropologization of the world, Pierre Clastres 


\section{AS FLAUTAS SAGRADAS NAS TERRAS BAIXAS DA AMÉRICA DO SUL E ALÉM}

A temática das flautas sagradas nas terras baixas da América do Sul é extremamente complexa, tudo começando com uma questão que não atinge somente essa região, mas todas as demais onde elas ocorrem. Trata-se de sua definição, mesmo que meramente instrumental, pois os objetos por ela circunscritos nem sempre são flautas no sentido organológico (conforme o sistema de Hornbostel-Sachs (Hornbostel e Sachs,1961[1914]), nem mesmo apenas aerofones, como eu mesmo já tornei evidente em pelo menos dois textos (Menezes Bastos, 2006; 2011). Por outro lado, sua qualificação como "sagradas" ou "rituais" pode ser vista como elusiva, como os mesmos escritos citados e muitos outros trabalharam. A complexidade da questão, porém, não se esgota aí, alcançando a extensão e o espalhamento de grande magnitude de sua ocorrência na região e muitas outras, dentre estas a Melanésia sendo um exemplo clássico (Cf. Hill e Chaumeil, 2011, e a nota 2, adiante). Devido a questões de escopo e de espaç̧o, abordarei aqui sua presença apenas em duas subáreas importantes de sua manifestação nas terras baixas, o Alto Xingu - focalizando os Xinguanos, tema central de meu estudo-e o Alto Rio Negro, limitando-me quanto a estes mui brevemente aos Tukano.

Estudo essas flautas entre os xinguanos desde 1978. De lá para cá, porém, escrevi apenas um trabalho especificamente direcionado a elas (2006). ${ }^{2} \mathrm{~A}$ falta de maior desenvolvimento de minha produção sobre o tema não constitui um fato isolado, pois ele somente começou a ser encarado mais especificamente nas terras baixas a partir dos trabalhos de Piedade (1998; 2004), Mello (1999; 2005) e Barcelos Neto (2002; 2008).

Em 1978, descrevi as flautas yaku'i - este é o seu nome em Kamayurá (alternativamente, yumiamáe) -, abordei sua posição no sistema de classificação de instrumentos musicais do grupo e estudei a relação entre seus três tocadores - o mestre central e os dois aprendizes laterais -, equiparando, por outro lado, o complexo dessas flautas, apanágio da comunidade masculina, à menstruação feminina, povoada de tabus no Alto Xingu. Esta equiparação foi feita com base na verificação de aspectos que exibem grande paralelismo entre os dois sistemas. Por exemplo, as mulheres menstruadas entre os Kamayurá não tomam banho de imersão. Da mesma maneira, os homens, enquanto envolvidos na execução das flautas. Similarmente, uns e outros não devem cozinhar. Por fim, eles não devem falar alto - mantendo comportamento discreto - nem publicizar sua condição de menstruados, para os homens isto significando dizer que eles, ou quaisquer outras pessoas, não devem dizer que estão tocando as flautas. Quando as flautas estão sendo executadas, tudo se passa como se não houvesse humano as fazendo soar.

Observe-se que, no anexo fotográfico do livro, precedido de uma nota sobre a não presença ali das yaku'i em execução - mas somente dos instrumentos, sem

2 | Neste livro-referência importante para a temática como um todo -, constam textos que têm especial interesse para o presente, entre os quais os de Piedade (2011), Mello (2011), Prinz (2011), o de minha própria autoria (Menezes Bastos, 2011), além da Introdução (1-46) ao livro. Meu texto de 2011 é uma revisão e versão ao inglês do de 2006 . 
executantes -, existem duas fotos delas. A nota diz que a falta de tocadores se devia à recomendação dos índios, adicionando que a visão por mulher da execução masculina das flautas seria algo de deselegante e perigoso para ambos. Na edição de 1999 d’A Musicológica (cf. Menezes Bastos 1999), no anexo as flautas já não comparecem em fotografias, a nota, entretanto permanecendo a mesma da edição original. Em 2006 (cf. Menezes Bastos, 2011 - para a versão revista em inglês), com base na análise de um episódio ocorrido nos anos 1950, extremamente sensível - o estupro coletivo de uma das esposas do então chefe da aldeia, esposa a quem chamei Pele de Reclusa ${ }^{3}$-, expandi o meu quadro interpretativo, estudando o mundo dos sentidos Kamayurá e suas relações com o universo político, as relações de gênero e a violência, expansão que com o tempo mostrou ter grande rendimento, conforme adiante ${ }^{4}$.

Os trabalhos dos três hoje colegas acima citados desde sua incepção mudaram substancialmente o que se sabia sobre as flautas sagradas no mundo xinguano, alcançando também grande interesse em relação às demais áreas, nas terras baixas e além: as flautas - rezava a mitologia xinguana, segundo eles - eram na realidade máscaras de espíritos que antes do grande cataclismo constituído pelo surgimento da luz no mundo viviam na escuridão do patamar subterrâneo, juntamente com os humanos e demais seres. A luz surgiu por obra dos gêmeos, Sol e Lua - filhos do demiurgo Mawutsini e mestres do xamanismo xinguano -, filhos antropomorfos de Onça e das também antropomorfas Mulheres de Pau criadas por encantamento pelo demiurgo. As entidades, yerupoho (em Wauja) - que após o cataclismo passaram a ser chamadas apapaatai-, chamadas de itseke em Kuikuro e mamáe em Kamayurá, no momento em que a luz surgiu construíram máscaras e as vestiram para protegeremse, pois a luz queimava a sua pele. Um aspecto crucial que a tese de Maria Ignez Cruz Mello (2005) esclareceu é que as mulheres não podem ver as flautas, mas devem escutá-las. Assim, é de se notar que tipicamente o repertório do ritual feminino do Amurikumã - estudado por Mello (cf. 2011, além de sua tese) -é integrado por canções que mantém com as respectivas peças instrumentais das yakú i uma relação similar à de transposição no sentido musicológico, graças ao esforço feminino de ouvir as músicas das flautas, gravá-las em suas memórias e depois torná-las em modelos por assim dizer mnemônicos de sua música vocals ${ }^{5}$ Observe-se que a mitologia, aspecto que eu conhecia desde a época do meu livro de 1978 (Menezes Bastos, 1978), apontava-me que as referidas flautas originalmente haviam sido roubadas dos mama'e pelas mulheres, os homens, entretanto, as tendo roubado delas depois. De qualquer sorte, tenham sido as mulheres ou os homens aqueles que as transformaram em posses exclusivas e distintivas, as flautas em estudo são, segundo a mitologia xinguana, resultado do cataclismo originante do mundo hoje, resultado que aponta para uma antropologização dele, uma vitória dos humanos - masculinos ou femininos, os dois, porém, estando sempre em conflito constitutivo - face aos espíritos. Elas constituem a partir daí um estratégico objeto de poder, o de controlar o interdito visual em comentário.

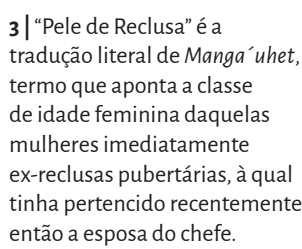

4 | Veja a tese de Mello, já citada. Ver também McCallum (1994) e Junqueira (1998).

5| Para os Kamayurá xinguanos em geral, a cabeça-tipicamente a memória-, através do ouvido, funciona como gravadores magnetofônicos, fixando o que captam. Ao que parece, todos os demais sentidos - isto é, visão, olfação, tato - têm o mesmo tipo de desempenho. 
Quanto ao Alto Rio Negro, os trabalhos, entre outros, de Hugh-Jones (1979), Piedade (1997; 1999) e Hill (1993a; 1993b) estão na base de minha visão sobre as flautas sagradas na sub-região, como disse tratadas aqui brevemente. $O$ texto de Hugh-Jones, hoje um clássico juntamente com o de sua esposa, Christine Hugh-Jones (1979), tornou-se paradigmático em relação à sub-região etnográfica, por elaborar um modelo teóricoetnográfico de fundo estruturalista para descortinar o universo indígena, tipicamente sua cosmopolítica. No caso das flautas e trompetes sagrados, o primeiro texto (HughJones, 1979) evidenciou a existência do que chama de um "culto" secreto masculino -com explícita exclusão feminina - espalhado por toda a sub-região, ligado a um conjunto complexo de instrumentos musicais, especialmente flautas e trompetes. Prefiro não adotar a categorização de "culto" para o universo de saberes e práticas ligadas às flautas e trompetes em análise, levando em conta as contenções levantadas em relação à ideia de culto religioso na região das terras baixas como um todo por Viveiros de Castro (1992: 6). Noto que esse universo de flautas e trompetes é conhecido em toda a região do Alto Rio Negro através da palavra Yurupari, em língua geral ou nheengatu.

Os trabalhos de Piedade (1997; 1999) enfatizam a ligação desses instrumentos sagrados a uma menstruação simbólica masculina, o que também acontece entre os Xinguanos - particularmente, os Kamayurá -, conforme apontei em meu livro de 1978. Essa maneira de divisar a temática tem um grande desenvolvimento na literatura sobre a Melanésia (cf. Hogbin, 1970; Herdt, 1981; 1982). Recordo que no Alto Xingu há uma inversão explícita entre rituais masculinos e femininos, os primeiros ligados às flautas sagradas, os segundos estando vinculados ao rito do Amurikumã e associados, conforme abordados por Mello (1999; 2005). De acordo com o segundo texto de Piedade, "a ausência da capacidade de engravidar entre os homens Tukano seria compensada simbolicamente através de seu poder ritual de fabricar homens no ritual de iniciação masculina" (: 4). Os Wakuenay, povo Arawak da mesma sub-região, partilham também esta marca (Hill, 1993a;1993b).

\section{O PERCURSO DAS FLAUTAS XINGUANAS}

A seguir, estudarei uma cadeia de eventos envolvendo as flautas xinguanas - no caso, Kamayurá - ora em estudo, cadeia esta que colocou e ainda coloca em interação a mim mesmo, alguns parentes - companheira, filhos, filhas e outros -, colegas e estudantes que trabalham ou trabalharam comigo, e alguns índios Kamayurá, inclusive Ayupu - residente entre os Yawalapití -, irmão júnior de Takumã, finado chefe Kamayurá que me presenteou com a flauta. O cenário da cadeia engloba Brasília, Londres, Florianópolis e as aldeias Kamayurá e Yawalapití - lugares de morada dessas pessoas -, ela tendo tido início em 1981, na aldeia Kamayurá, quando seu chefe me presenteou com uma yakúí. Tem sido o estudo dessa cadeia que tem me propiciado a compreensão das yakú i que ora apresento. 
Em 1981, quando eu fazia trabalho de campo em Yawaratsingtùp, aldeia Kamayurá também conhecida como Ipawu, o finado chefe Takumã, meu anfitrião, ofereceu-me uma yaku'i. Eu havia pedido a ele uma delas para com ela presentear um parente. De volta a Brasília - onde eu residia -, foi o que fiz, oferecendo-a ao parente. Não era rara, então, a prática de visitantes ao então Parque Nacional do Xingu-dirigido originalmente por Orlando Vilas-Boas-, hoje Terra Indígena do Xingu, voltarem a seus lugares de origem com, entre outros itens, um desses objetos ilustres do mundo xinguano. Não parecia pesar sobre essas flautas que saiam o mesmo tipo de restrição à visão feminina vigente entre os próprios indígenas no caso da visão delas por não-índias fora dos limites da área indígena. Este tipo de, por assim dizer, afrouxamento de restrições, acontecia também em outros domínios - por exemplo, fora desses limites, xinguanos ou xinguanas comerem carne de animal de pelo podia ocorrer, o que de forma alguma acontecia domesticamente. Talvez, ao invés de supor afrouxamento de restrições, seria o caso aqui de pensar que o modo de ser Kamayurá admitiria variações externas em relação aos costumes adotados internamente, as referidas variações podendo às vezes ser muito grandes.

Note-se que, àquela altura, eu sabia muito pouco sobre essas flautas, cuja tematização deu-se, como se viu, somente muito depois na literatura etnológica nas terras baixas da América do Sul. Sabia que as mulheres não as deviam ver, sob pena de estupro coletivo. Eu não tinha nenhuma hipótese sobre os porquês desta interdição, senão a pura verificação de que a mulher que as visse corria perigo - a do estupro coletivo. Sua equação, por outro lado à menstruação feminina - o que estabeleci a partir de inspiração melanesiana (conforme originalmente Hogbin, 1970)-, somente ela, não me levava muito adiante. Como disse, esta situação começou a mudar com as pesquisas dos três hoje colegas, Piedade (2004), Mello (1999; 2005) e Barcelos Neto (2002; 2008) - que tive o gosto de acompanhar -, da consideração do meu próprio material etnográfico inédito, de meus textos publicados, a começar por aquele de 1978, assim como do conhecimento adquirido por meio de meus contatos contínuos, em campo ou não, em cidades como Brasília, São Paulo e outras, com os Kamayurá e outros xinguanos. Em 1978, descrevi as flautas, estudei a relação entre seus três tocadores - o mestre central e os dois aprendizes laterais, equiparando, por outro lado - como acima dito-, o complexo dessas flautas, apanágio da comunidade masculina, à menstruação feminina, povoada de tabus no Alto Xingu.

Apesar dessa expansão do quadro interpretativo, no plano propriamente empírico minha abordagem permanecia quase a mesma do começo. Perguntava eu, então, a mim mesmo: o que seriam, enfim, as yakúi, por que elas não deviam ser vistas pelas mulheres e por que e como elas constituíam uma trindade? Observo que este último ponto foi por mim analisado em 1978 com base nas regulamentadas relações de parentesco vigentes entre os integrantes do trio de tocadores, a saber, de afinidade e consanguinidade entre ego, o maraka ùp, "mestre de música", sempre ao centro da 
formação coreográfica, e seus "aprendizes", respectivamente à esquerda (afim) e direita (consanguíneo) de ego. Ainda no texto de 2006, adicionalmente, ensaiei o insight de que o estupro coletivo da esposa do então chefe Kamayurá - em affair amoroso com Leonardo Villas Boas - fora provocado pela visão das flautas por ela, o que desencadeou a transformação de seu namorado e dos homens Kamayurá em uma comunidade de yaku' i, sob o império de sua ética e política, ferozes em relação à visão das mulheres. Manga'uhet e Leonardo Villas Boas tinham seus encontros amorosos, testemunhados à distância por quem quisesse na aldeia, na casa onde residia Leonardo. Um trio de yaku'i fora posto na casa, transformando-a em um tapui, "casa das flautas", ao tempo em que transformava Leonardo, ele mesmo, numa flauta.

A questão da colocação das flautas na casa de Leonardo é complexa e delicada, colocando sob perspectiva a própria natureza delas. Já tratei dela, embora inicialmente, em meu texto de 2006, e agora a elaboro um pouco mais. Tudo começa, segundo penso, em afastar a ideia simplista e preconceituosa de que se está aqui em face de um mero crime passional, perpetrado por um pretensamente ciumento Kutamapù contra uma pretensa esposa traidora e seu suposto namorado. Note-se que Leonardo foi expulso da aldeia, Mangáuhet tendo sido vítima de um feroz - vale recordar a etimologia desta palavra, "fera" - estupro coletivo, a partir do qual sofreu o ostracismo, indo residir entre os Karajá, na Ilha do Bananal, onde se casou e mora até hoje, de vez em quando indo à aldeia Kamayurá visitar parentes. Em 2000, tive a oportunidade de encontrar com ela nesta aldeia.

Uma versão do que ocorreu é a de que o trio de flautas em comentário foi colocado na casa de Leonardo a pedido de Kutamapù, para que Pele de Reclusa o visse quando de suas idas ali para namorar com Leonardo. Vários interlocutores, porém, dizem que o trio foi para lá por agência própria. De qualquer sorte, o chefe havia sido vítima, segundo os Kamayurá, de um ato de guerra por parte de Leonardo, ato que exigia vingança. Como coloquei em Menezes Bastos (2006) e agora reitero, a infidelidade conjugal no plano interétnico trata-se de um ato de guerra, equacionado com o roubo de mulheres. Diferentemente do que se passa no nível intraétnico-quando ele é facilmente resolvido, quase como apenas uma rusga -, no campo interétnico ele é visto como um ataque extremamente violento proveniente de inimigo externo. $\mathrm{O}$ estupro, assim, de Pele de Reclusa tratou-se de uma vingança do povo Kamayurá por meio de seus homens, transformados numa comunidade feroz de yakúi.

Conforme já comentado, os trabalhos dos colegas acima citados mudaram o que se sabia sobre as flautas yaku'i: o surgimento da luz por obra de Sol e Lua provocava a queimadura das peles dos yerupoho, estes após o cataclismo passando a usar máscaras. Assim, o primeiro e crucial ponto de minha ignorância quanto às flautas estava sendo sanado - as yaku'i i eram na realidade máscaras dentro das quais habitavam espíritos, pisciformes, exímios músicos e exigentes apreciadores de sua própria música, que não deve ser executada com erros, sob pena de sua fúria. Lembro que o repertório do ritual 
feminino do Amurikumã é formado por canções que são como que transposições vocais das respectivas músicas das flautas sagradas. Permanecia a questão, porém: porque a proibição somente à visão das flautas pelas mulheres? Por que as mulheres e, não, os homens? Mulheres e homens estão no mesmo patamar ontológico e político? O que significa ver para os Wauja? E ouvir? Observe-se que a mitologia, que eu conhecia desde a época do meu livro de 1978, apontava-me que as referidas flautas originalmente haviam sido apropriadas pelas mulheres, os homens as tendo roubado delas depois. De qualquer sorte, tenham sido mulheres ou homens aqueles que as transformaram em posses exclusivas e distintivas, as flautas em estudo são, segundo a mitologia, resultado do cataclismo a partir do qual originou-se o mundo de hoje, os humanos passando à superfície iluminada sendo que os mamáe continuaram no patamar inferior, passando a incursões à superfície apenas eventualmente, quando passaram a causar doenças e mortes aos humanos. Tal o sentido dessa antropologização: a hegemonização dos humanos face aos mamáe. As flautas vão constituir a partir daí um estratégico objeto de poder, o gênero que as aproprie tendo posição vantajosa, sempre contestada, porém.

A tese de Piedade traz importantes avanços acerca da problemática da visão por mulheres das flautas yakú i e sobre o tema da visão em geral entre os Wauja. De acordo com o autor, o mundo da superfície, onde hoje vivem os humanos é abruptamente separado daquele onde habitam os espíritos yurupoho, no escuro patamar inferior, um exílio. A luz, com a visão - assim como o domínio do fogo-, constitui no mundo hoje a recordação contínua e perene da quebra da antiga hegemonia dos yurupoho face aos humanos, o que também o livro de Barcelos Neto (2008), sustenta. Com a luz e a visão, deu-se a apropriação das flautas pelos humanos - indiferentemente homens ou mulheres, sempre politicamente clivados, porém, deve-se sempre notar-, o que veio a selar a hegemonia desses face aos espíritos, apontando para, conforme disse acima, uma antropologização do mundo, com explicitação ao nível das relações de poder.

A flauta que presenteei a meu parente foi colocada em local discreto, uma sala de jantar reservada e formal, em sua casa em Brasília. Passaram-se muitos anos sem que eu ouvisse falar dela, o que somente aconteceu em 2018 - então, o presenteado passou a entender que a flauta era um objeto muito importante para estar reduzido à mera hospedagem em sua casa. Uma de minhas filhas - sua sobrinha-, em contato com ele, reportou-me esse entendimento do presenteado, o que me levou a providenciar a devolução da flauta aos Kamayurá. Por meio de João Albuquerque de Almeida (2019) - o doutorando xinguanista referido na nota 1-, ela foi levada para Ayapu Kamayurá, residente na aldeia Yawalapití e irmão caçula de Takumã. Ambos haviam sido flautistas e construtores de yaku'i i, cuja fabricação envolve um grande domínio dos saberes dos universos mito-músico-cosmológico, da percepção musical e liuteria. Note-se que Ayupú, quando adolescente, chegou a aprender a confecção da yakú i com seu pai, o que também aconteceu com o finado Takumã, este sendo um virtuose na sua execução, 
até os anos 1990, como pude testemunhar. Ser executante dessa flauta-ou de qualquer outro instrumento musical - não parece ser um fato necessariamente para toda a vida do sujeito, dependendo da duração de sua relação com os espíritos que a habitam. Recordo que desde os anos 1970 até os 1990, Takumã era considerado um virtuoso da yakú i, consagrado entre todos os xinguanos. Ele tinha o raro privilégio de muitas vezes tocar em solo, o que não é corriqueiro. Na aldeia Yawalapití, Ayupú tornou-se o dono (em Kamayurá, -yat) da flauta kuluta (em Kamayurá, kuruta), similar à yakúi (veja meu texto de 1978), mas sem tantos interditos às mulheres. Ayupú pretende queimar a flauta yaku' i devolvida que recebeu, para depois fabricar três novas e assim tornar-se dono dela e logo promover o seu ritual. Note-se que ele, tendo aberto a flauta que foi por mim devolvida a ele, verificou que ela foi feita pelo pai de Takumã, o antigo chefe Kutamapù, esposo de Pele de Reclusa.

\section{ANTROPOLOGIZAÇÃO DO MUNDO}

O que quero dizer com antropologização do mundo, isto em um universo onde o homem, especificamente conforme a tematização kantiana, de acordo com a abordagem de Foucault (1999), não tem lugar? Nesta questão, o cerne deste pequeno texto. Recordo que Foucault aponta nesse clássico que o que chama de tematização kantiana do homem é produzida por Kant em suas célebres Críticas. É a partir delas que o "homem" kantiano passa a ter existência. A seguir, apresento uma breve história desta problemática na minha versão de xinguanista. Em Menezes Bastos 2013 (cf. 2012), retomando uma questão que me ocupa há muito tempo, a obsessão xinguana pela sensorialidade, afirmei que essa obsessão é tão forte que chega a constituir um estado de vigilância capilar - envolvendo todos os sentidos - que parece apontar para uma disciplina que abarca todos os domínios da vida social ${ }^{6}$ Conclui gravemente que os xinguanos poderiam ser caracterizados como sociedades disciplinares. Usei esta noção inspirado em Foucault (cf. Deleuze, 1996). Uma sociedade disciplinar, mas, veja-se, contra a modernidade, conforme a concepção de Clastres (1978) desta contrariedade ou recusa. Observe-se que a ênfase nesse estado de vigilância está evidenciada em etnografias xinguanas clássicas, como as de Quain (Murphy e Quain, 1966) e Gregor (1977) - neste livro, estando presente desde a penetrante foto da capa que exibe um recluso pubertário olhando através de uma fresta -, tudo ali se passando, como eu disse uma vez, "como se a uma abrangente lógica das qualidades sensíveis (conforme seminalmente posto por Lévi-Strauss) se somasse uma onipresente biopolítica da sensorialidade" (Menezes Bastos, 2012; 2013). Note-se que os dois últimos textos trazem farta etnografia no sentido de evidenciar essa onipresença da biopolítica, em contraponto com a referida lógica lévi-straussiana7.

As versões dos mitos wauja colhidas por Mello (ver especialmente 1999: 67-69) e Barcelos Neto (particularmente, 2008: 51-68) sustentam como as relações dos humanos
6| Maria Ignez Cruz Mello, ainda quando minha aluna no doutorado, e eu conversamos várias vezes sobre esta temática. Eu Ihe sugeria cautela no sentido de não confundir os ameríndios com os modernos europeus. Volto a dizer que sou o único responsável por tudo o que vai neste texto.

7|Venho continuamente trabalhando essa dupla abrangência (a da lógica das sensibilidades e a da biopolítica da sensorialidade) desde o meu livro de 1978 até o de 2019. 
com os yerupoho sofreram profundas mudanças com o cataclismo da aparição da luz e a concomitante posse do controle do fogo pelos heróis antropomorfos gêmeos Sol e Lua, e sua doação aos humanos. Na escuridão, os yerupoho eram hegemônicos. Com a luz e o controle do fogo, os humanos assumiram esse papel, migrando para a superfície juntamente com os animais, plantas e tudo o mais. Os yerupoho permaneceram no escuro mundo inferior. Este é o ponto principal que gostaria de reter para ir adiante-a transfiguração das relações, tipicamente, de poder, entre os humanos e os yerupoho, logo transformados em apapaatai, com a invenção da luz somada ao controle do fogo. Conforme formula Barcelos Neto (2008: 65), a partir daí os humanos acenderam à superfície e os yerupoho continuaram no patamar inferior, transformando-se em monstros ocultos, aterrorizadores e causadores de doença e morte aos humanos.

A leitura que faço da ideia clastriana de (sociedade) contra o Estado supõe que o Estado está presente também nesse tipo de sociedade outrora concebidas como carentes de Estado, como, aliás, Clastres deixa claro em sua argumentação. Quer dizer, o Estado está ali em potência - no caso, uma proibição ou interdição-, através do chefe de guerra - permitido de existir somente durante a guerra -, sendo, por assim dizer, exorcizado a cada momento em que ameaça perpetuar-se. ${ }^{8}$ Opero com um tipo similar de entendimento para pensar a ideia de modernidade, que compreendo com base nas formulações de Latour (1994). Trata-se de elaborar a modernidade como também uma potência - de novo, no caso, uma proibição, interdição -, sempre presente nas sociedades tradicionais, essa interdição encontrando no controle da proliferação dos híbridos - pertinentes tanto à natureza quanto à cultura - sua possibilidade de concretização. Recordo que Latour em seu clássico de 1994 (1991) parte do princípio de que o conceito de modernidade supõe a articulação de dois universos distintos, um deles - assentado na prática de tradução - englobando seres híbridos de natureza e cultura. O segundo-ancorado na prática de purificação - instaura duas zonas ontológicas diferentes, a dos humanos e a dos não humanos. Para ele, o mundo da modernidade supõe a separação dessas práticas, sendo a purificação a operação que impede a proliferação de híbridos de natureza e cultura.

Para elaborar as ideias de Latour sobre a modernidade no que tange ao mundo xinguano, começo por recordar que em 1969, data de meu primeiro trabalho de campo ali, o universo das modernas técnicas de reprodução (Benjamin, 1969) era sensivelmente perigoso para eles, esse mundo sendo acionado então através tipicamente das máquinas fotográfica e cinematográfica e do gravador magnetofônico, perigosíssimos, pois aprisionadores da alma (ang) e da linguagem (yéeng). Note-se que "fotografia" na língua Kamayurá se diz ang, "alma", o composto desta palavra, táangap, "imagem", tendo especial lugar no mundo do xamanismo (cf. Menezes Bastos, 1985). Por outro lado, a categoria yéeng, "linguagem", em Kamayurá (como tenho trabalhado desde 1978) - mas não só, conforme Montardo (2009) evidenciou para o mundo Guarani, através do estudo de um termo cognato-aponta para o sentido amplo de "linguagem"

8 | Essa ideia tem sido objeto de uma vasta literatura, recentemente o dossiê organizado por PerroneMoisés, Sztutman e Cardoso (2011) sendo um exemplo. 
que abarca não somente o universo verbal, mas também a musicalidade e a dança, apontando o sentido geral de horizonte da presentação da subjetividade dos entes.

Retornando, então, à minha primeira visita aos Kamayurá, em 1969, tratava-se então que as referidas máquinas de reprodução produziam à sensibilidade indígena verdadeiros horrores aos universos tanto da ang quanto da yéeng, entronizando o mundo da cópia como simulacro, lugar absurdo de encontro da plena similitude com a completa diferença em relação ao original, ao idêntico (Deleuze, 1968), possuidor de aura. Note-se que hoje as referidas máquinas foram por assim dizer domesticadas pelos xinguanos e muitos outros grupos indígenas espalhados pelas terras baixas, muitos indígenas, aliás, sendo atualmente festejados artistas do campo dessas artes. Conforme antes elaborei - vide também a nota 5 deste texto-, o mundo dos sentidos para os Kamayurá é absolutamente estratégico, fato a partir do qual elaborei a teoria que aponta ali a vigência de disciplinas que abrangem toda a vida social (2012; 2013). Aqui está a chave de toda a questão que este texto procura elaborar e que eu formulei, conforme antes dito, em torno de uma lógica das qualidades sensíveis somada a uma onipresente biopolítica da sensorialidade.

Entendo que entre os xinguanos a expressão antropologização do mundo caracterizada pela inversão das relações de poder entre os humanos e os yerupoho - carrega de maneira plena a aliança de uma lógica do sensível com a biopolítica da sensorialidade. As relações de gênero são determinantes em todo esse universo, sempre clivados, divididos, em conflito - sem possibilidade de soma zero-, envolvendo alternativamente humanos mulheres e homens e-sine qua non-espíritos. Como já dito, no tempo mítico tudo teve início com as mulheres, as humanas que por primeiro apropriaram-se das flautas. Elas logo, porém, foram roubadas pelos homens - a irreciprocidade domina as relações entre os gêneros desde este tempo. Este contraponto entre o masculino e o feminino é completamente congruente com o contraponto existente entre a música das flautas yakưi i, hoje masculina (pois originalmente feminina, conforme a mitologia), e aquela dos gêneros musicais - vocais por excelência - ligados ao ritual feminino do Yamurikumã, e associados, conforme estudado por Mello (ver sua tese de doutorado e seu artigo de 2011) e Franchetto e Montagnani (2011; 2012; 2014).

As relações de gênero entre os xinguanos foram estudadas, entre outros, por Quain (Murphy e Quain 1966) e Gregor (1977), Basso (1985), mais recentemente tendo sido abordadas nos estudos de Mello (1999; 2005; 2011), Piedade (principalmente na tese), McCallum (1994), Junqueira (1996), Franchetto (1996) e Nogueira e Fonseca (2013), bem como nos textos acima citados de Franchetto e Montagnani. Eu também as venho considerando desde o início, de maneira, porém, tangencial. Parece haver um consenso entre esses autores de que essas relações são caracterizadas pela assimetria, uma assimetria muitas vezes expressa por meio da irreciprocidade, dominada pelo roubo e pela violência, esta última tendo o estupro coletivo como o mais eloquente canal. 
A posse exclusiva e diferencial das flautas sagradas é índice crucial aqui. $O$ acesso ao xamanismo somente - seria melhor dizer predominantemente - pelos homens também está presente a marcar essa profunda assimetria, rompida, entre outros fatores pela liberalidade (para homens e mulheres, indiferentemente) das relações sexuais extraconjugais no plano intraétnico. A propósito, note-se que no affair envolvendo Pele de Reclusa e Leonardo Villas Boas, a reclamação do chefe Kamayurá a Villas Boas era a de que Leonardo desejava sua esposa somente para ele - o chefe nada tinha contra o affair em si, somente contra a exclusividade que Villas Boas desejava ter em relação à sua esposa. Vale apontar que hoje os Kamayurá têm uma xamã muito reconhecida, Mapulu, filha do falecido Takumã, que além de chefe era um poderoso xamã. Note-se que este parece ser, porém, apenas um caso de xamanismo exercido por mulher, já que a maioria de xamãs é de homens.

Conforme o presente estudo, as relações de gênero não se congelam no plano tão somente dos humanos, sofrendo um corte profundo com a entrada em cena, constante e constitutiva, das yaku'i i. Não cabe dúvida que as flautas são de madeira e, assim, pois, pertinentes ao domínio vegetal. Mas isto não lhes basta, pois elas são máscaras que embutem mamáe, "espíritos" que lhes efetiva a musicalidade. São elas, assim, híbridas de natureza e sobrenatureza. Note-se que elas mesmas-quero dizer, os espíritos que habitam seu interior - são pura música, irrompendo tipicamente das águas lacustres e fluviais, como pelo menos uma vez eu mesmo pude testemunhar, sem nada ouvir, entretanto (veja meus textos de 2012 e 2013). Entendo que esse corte das flautas nas relações de gênero xinguanas é absolutamente fundamental para a definição de sua natureza e substância híbrida de natureza e sobrenatureza, como visto o campo do poder sendo aqui básico.

Em artigos anteriores (2012: 18; 2017), pensando sobre as prioridades de uma agenda de pesquisa para a etnologia das terras baixas da América do Sul, salientei a importância do estudo concatenado dos universos rituais, com suas respectivas cadeias intersemióticas, tudo ligado à aproximação da percepção sonoro-musical e da intersensorialidade, como base do que denominei biopolítica da sensorialidade. Por fim, registrei também como prioritária a abordagem do processo de variação musical - do qual tanto tenho tratado, como também Piedade e Mello-, com o seu cruzamento com o de transformação na acepção de Lévi-Strauss. Last but not least, registrei o interesse estratégico da investigação dos processos de comunicação sonoro-linguístico-musical, que não somente envolvem os "humanos", mas tem alcance trans-específico, incluindo "animais", assim como "seres inanimados" e "espíritos". Em seguida, levantei algumas questões que de imediato vieram-me à mente: "do que se trata, exatamente, aquilo que anteriormente apontei como "um tipo de ouvido absoluto"? Qual o limiar auditivo entre os grupos ameríndios das terras baixas da América do Sul? Que percepção auditiva é esta que não somente recebe como intencionalmente rastreia e capta os sons?"9 Noto que já no resumo desse texto eu apontava "para a necessidade urgente
9| Noto que perguntas como essas têm orientado minhas investigações desde 1978. Explico que "ouvido absoluto", fenômeno ao que parece raro no Ocidente, é a capacidade - ou a limitação, depende do ponto de escuta-de ouvir e representar diapasonicamente o que foi ouvido. 
de novas pesquisas na região sobre a percepção acústico-musical (e a percepção em geral), o universo do ritual e suas conexões com o mundo do poder e do político" (: 5). Em 2013, participando de uma memorável coletânea onde o perspectivismo ameríndio era central (Brabec de Mori e Seeger, 2013), desenvolvi e reforcei o que elaborei em 2012, enfatizando a importância estratégica que a politicidade deveria ter nos estudos sobre o perspectivismo. É evidente que o presente estudo sobre as yakúi tem na politicidade das relações entre homens, mulheres e espíritos a sua base mais elementar, o que os estudos pioneiros de Mello, Piedade e Barcelos Neto - aqui fartamente usados avançaram, antecipando muito daquilo que Sztutman (2020) elabora.

Nesse texto, esse autor elabora as bases de uma aproximação política do perspectivismo, apontando de uma maneira muito fértil para uma amerindianização da própria política. Considero essa perspectiva muito importante e compreendo que a política nas suas miríades de elaborações indígenas, da Patagônia ao Alaska, tem sido um campo absolutamente estratégico para os povos ameríndios, ainda mais quando associado aos desdobramentos rituais e musicais explorados por mim em diversos trabalhos. ${ }^{10}$

Rafael José de Menezes Bastos é Professor Titular, aposentado, voluntário, Departamento de Antropologia, Universidade Federal de Santa Catarina (UFSC).

CONTRIBUIÇÃO DE AUTORIA: Não se aplica

FINANCIAMENTO: Bolsista CNPq 1B, bolsa e taxas de bancadas

\section{REFERÊNCIAS BIBLIOGRÁFICAS}

ALMEIDA, João Albuquerque de. 2019.

Entrevista com Ayupú sobre suas intenções para a flauta yaku,i. Manuscrito.

ALMEIDA, João Albuquerque de. 2020. Comunicação Pessoal.

BARCELOS NETO, Aristóteles. 2002.

A Arte dos Sonhos: Uma Iconografia

Ameríndia. Lisboa: Assírio \& Alvim.
BARCELOS NETO, Aristóteles. 2008. Apapaatai: Rituais de Máscaras no Alto Xingu. São Paulo: Editora da Universidade de São Paulo.

\section{BASSO, Ellen. 1985. A Musical View of the} Universe: Kalapalo myth and ritual performances. Philadelphia: University of Pennsylvania Press,

BENJAMIN, Walter. 1969 (1936). "A Obra de Arte no Tempo de suas Técnicas de Reprodução", in: VELHO, Gilberto (org).. Sociologia da Arte, IV. Rio de Janeiro: Zahar, pp. 15-47.
10| Permito-me considerar brevemente o meu próprio trabalho, feito desde o começo, em 1969, com os índios. Recordo que A Musicológica tem 42 anos de publicada, seus direitos autorais tendo sido divididos com os Kamayurá. Veja Jacques (2016) para uma extensa resenha sobre esse livro nos seus quarenta anos de idade. Vale considerar que esse trabalho resultou em uma dissertação, uma tese, dois livros (registro que "A Festa da Jaguatirica" foi lançada na aldeia Kamayurá, simultaneamente cerca de 50 cópias desse livro tendo sido doadas a eles) e cerca de cento e dez artigos, mas também em um acervo fonográfico de larga duração na maioria das vezes de excelente qualidade acústica. Uma cópia integral dele foi doada aos índios. Infelizmente, um incêndio de grandes proporções que queimou seis casas residenciais incendiou também a cópia integral dos cerca de noventa CDs onde o acervo estava gravado. Logo em seguida providenciei outra cópia, doando-a aos Kamayurá de novo. Vale observar que felizmente no final dos anos 1990 eu havia doado as gravações originais do referido acervo ao Museu Osvaldo Rodrigues Cabral da UFSC aos cuidados da colega Deise Lucy Montardo, que as digitalizou integralmente (É esse acervo que, integrado à documentação do Museu, recentemente foi antropo-arquivisticament arrumado e organizado pela colega Luisa Valentini, tendo sido objeto de um dos capítulos de sua tese de doutorado na USP, defendida em 2019 (Valentini, 2019). Em 2019, tive o imenso gosto de receber em minha casa em Florianópolis, entre 12 e 19 de maio, a visita de Luisa Valentini, Mayaru Catão Kamayurá, Auakamõ Kamayurá e Marcelo Kamayurá para conversar sobre esse acervo e suas conexões com o seu próprio mundo. Foi um conjunto de encontros de grande relevância para aprofundar o conhecimento do acervo e a percepção e destinação indígenas do mesmo. 
artigo | Rafael José de Menezes Bastos | Sobre as flautas sagradas xinguanas e a antropologização 13 do mundo

BRABEC DE MORI, Bernd; SEEGER, Anthony (org). 2013. "Introduction: Considering Music, Humans, and Non-humans" The Human and Non-Human in South American Music". Ethnomusicology Forum, Special Issue, v. 22, n. 3: 269-286. DOI: https:// doi.org/10.1080/17411912.2013.844527

CLASTRES, Pierre. 1978 (1974). "A Sociedade contra o Estado”. In: CLASTRES, Pierre. A Sociedade contra o Estado: Pesquisas de Antropologia Política. Rio de Janeiro: Francisco Alves, pp. 132-52.

DELEUZE, Gilles. 1968. Différence et Répétition. Paris: Presses Universitaires de France.

DELEUZE, Gilles. 1996. “Un Nouveau Cartographie" ("Surveiller et Punir")". In DELEUZE, Gilles. Foucault. Paris: Minuit, pp. 31-51.

FOUCAULT, Michel (1999 [1999]). As palavras e as coisas: uma arqueologia das ciências humanas, tradução brasileira, $8^{a}$ ed. São Paulo: Martins Fontes.

FRANCHETTO, Bruna. 1996. "Mulheres entre os Kuikuro". Revista de Estudos Feministas v. 4, n.1: 35-54. DOI: https://doi.org/10.1590/\%25X

FRANCHETTO, Bruna; MONTAGNANI, Tommaso. 2011. "Flûtes des Hommes, chants des femmes Images et relations sonores chez les Kuikuro du HautXingu". Gradhiva, v. 13: 95-111. DOI: https:// doi.org/10.4000/gradhiva.2052

FRANCHETTO, Bruna; MONTAGNANI, Tommaso. 2012. "When Women Lost Kagutu Flutes, To Sing Tolo Was All They Had Left: gender relations among the Kuikuro of Central Brazil as revealed in ordeals of language and music". Journal of Anthropological Research v. 68, n. 37: 339-355. DOI: https://doi. org/10.3998/jar.0521004.0068.303
FRANCHETTO, Bruna; MONTAGNANI, Tommaso. 2014. "Langue et musique chez les Kuikuro du Haut-Xingu". Cahiers d'Anthropologie Sociale, v. 10: 54-76. DOI: https://doi.org/10.3917/cas.010.0054

GREGOR, Thomas. 1977. Mehinaku: The Drama of Daily Life in a Brazilian Indian Village. Chicago: University of Chicago Press.

HERDT, Gilbert H. 1981. Guardians of the Futes: idioms of masculinity. New York: McGraw-Hill.

HERDT, Gilbert H. (Org.). 1982. Rituals of Manhood: male initiation in Papua, New Guinea. Berkeley: University of California Press.

HILL, Jonathan D. 1993a. "Metamorphosis: Mythic and musical modes of ceremonial exchange among the Wakuénai of Venezuela". In: KUSS, M. (Org.). A Universe of Music: a world history. Washington: Smithsonian Institution Press.

HILL, J. D. 1993b. Keepers of the sacred chants: the poetics of ritual power in an Amazonian society. Tucson: University of Arizona Press.

HILL, Jonathan; CHAUMEIL Jean-Pierre (eds). 2011. Burst of Breath: Indigenous Ritual Wind Instruments in Lowland South America. Lincoln: University of Nebraska Press.

HOGBIN, Ian. 1970. The Island of Menstruating Men: Religion in Wogeo, New Guinea. Scranton: Chandler.

HORNBOSTEL, Eric. M.; SACHS, Curt.1961[1914]. "Classification of Musical Instruments" (English Version), Galpin Society Journal, v. 14: 3-29. DOI: https://doi.org/10.2307/842168

HUGH-JONES, Stephen. 1979. The Palm and the Pleiades: Initiation and Cosmology in Northwest Amazonia. Cambridge: Cambridge University Press. 
artigo | Rafael José de Menezes Bastos | Sobre as flautas sagradas xinguanas e a antropologização

do mundo

HUGH-JONES, Christine. 1979. From the Milk River: Spatial and Temporal Processes in Northwest Amazonia. Cambridge: Cambridge University Press.

JACQUES, Tatyana de Alencar. 2016. "Relendo 'A Musicológica Kamayurá', de Rafael José de Menezes Bastos: 40 Anos Para Além de uma Antropologia Sem Música e de uma Musicologia Sem Homem". Gesto, Imagem e Som: Revista de Antropologia, v. 1: 280-289. DOI: https://doi. org/10.11606/issn.2525-3123.gis.2016.116379

JUNQUEIRA, Carmem. 1998. "O Poder do Mito", Intercâmbio. Revista do Programa de Estudos Pós-Graduados em Linguística Aplicada e Estudos da Linguagem. vol 7. pp:103-111.

LATOUR, Bruno. 1994 (1991). Jamais fomos modernos: Ensaios de Antropologia Simétrica. Rio de Janeiro: Editora 34.

MCCALLUM, Cecilia. 1994. "Ritual and the Origin of sexuality in the Alto Xingu". In: HARVEY, Penelope; COW, Peter. (eds.) Sex and Violence: Issues in Representation and Experience. London: Routledge.

MELLO, Maria Ignez Cruz. 1999. Música e Mito entre os Wauja do Alto Xingu. Florianópolis, Dissertação de Mestrado, Universidade Federal de Santa Catarina. http://repositorio.ufsc. br/xmlui/handle/123456789/80830 (Acesso em 30/03/2021)

MELLO, Maria Ignez Cruz. 2005. lamurikuma: Música, Mito e Ritual entre os Wauja do Alto Xingu. Florianópolis, Tese de doutorado, Universidade Federal de Santa Catarina. http://repositorio. ufsc.br/handle/123456789/102877 (Acesso em 30 de março de 2021)

MELLO, Maria Ignez Cruz. 2011. “The Ritual of lamurikuma and the Kawoká Flutes". In: HILL, Jonathan; CHAUMEIL,
Jean-Pierre. (orgs). Burst of Breath: New Research on Indigenous Ritual Flutes in Lowland South America. Lincoln: University of Nebraska Press, pp. 257-276.

MENEZES BASTOS, Rafael José de. 1978. A Musicológica Kamayurá: para uma antropologia da comunicação no Alto Xingu. Brasília: Fundação Nacional do Índio.

MENEZES BASTOS, Rafael José de. 1985. "O 'Payemeraka' Kamayurá: Uma Contribuição à Etnografia do Xamanismo no Alto Xingu". Revista de Antropologia vol. 27-28: 139-178. Disponível em: http://www.etnolinguistica. org/biblio:bastos-1985-payemeramaraka. Acesso em 30 de março de 2021.

MENEZES BASTOS, Rafael José de. 1999. A Musicológica Kamayurá: Para uma Antropologia da Comunicação no Alto Xingu, $2^{\mathrm{a}}$. Edição. Florianópolis: Editora da UFSC.

MENEZES BASTOS, Rafael José de. 2006. "Leonardo, A Flauta: uns sentimentos selvagens". Revista de Antropologia v. 49, n. 2: 557-579. DOI: https://doi.org/10.1590/ So034-77012006000200002

MENEZES BASTOS, Rafael José de. 2011, "Leonardo, the Flute: on the Sexual Life of Sacred Flutes among Xinguano Indians", In HILL, Jonathan; CHAUMEIL, Jean-Pierre. (orgs) Burst of Breath: New Research on Indigenous Ritual Flutes in Lowland South America. Lincoln: University of Nebraska Press, pp. 69-91.

MENEZES BASTOS, Rafael José de. 2012. "Audição do Mundo Apùap II Conversando com "Animais", "Espíritos" e outros Seres. Ouvindo o Aparentemente Inaudível, Antropologia em Primeira Mão, v. 134: 5-21. Disponível em:https:// antropologiaprimeiramao.paginas.ufsc. br/files/2012/11/134_rmbastos_audicao. pdf Acesso em: 30 de março de 2021. 
artigo | Rafael José de Menezes Bastos | Sobre as flautas sagradas xinguanas e a antropologização

do mundo

MENEZES BASTOS, Rafael José de. 2013. "Apùap World Hearing Revisited: Talking with 'Animals', 'Spirits' and other Beings, and Listening to the Apparently Inaudible", In Ethnomusicology Forum v. 22, n. 3: 287-305. DOI: https://doi. org/10.1080/17411912.2013.845364

MENEZES BASTOS, Rafael José de. 2017. "Tradução intersemiótica, sequencialidade e variação nos rituais musicais das terras baixas da América do Sul". Revista de Antropologia v. 60, n.2: 342-355. DOI: https:// doi.org/10.11606/2179-0892.ra.2017.137312

MENEZES BASTOS, Rafael José de. 2019. A Festa da Jaguatirica: Uma Partitura CríticoInterpretativa, $2^{\text {a }}$ Ed. Florianópolis: Editora da Universidade Federal de Santa Catarina.

MONTARDO, Deise Oliveira. 2009. Através do Mbaraka: Música, Dança e Xamanismo Guarani. São Paulo: Edusp.

MURPHY, Robert F.; QUAIN, Buell. 1966. The Trumai Indians ofCentral Brazil. Seattle e Londres: University of Washington Press.

NOGUEIRA, Isabel; FONSECA, Susan Campos (org), 2013. Estudos de Gênero, Corpo e Música: Abordagens Metodológicas. Goiânia/Porto Alegre: Associação Nacional de Pesquisa e Pós-Graduação em Música. Série Pesquisa em Música, vol. 3. Disponível em: https://www.anppom.com.br/ebooks/ index.php/pmb/catalog/view/3/4/241 Acesso em 30 de março de 2021.

PERRONE-MOISÉS, Beatriz; SZTUTMAN, Renato; CARDOSO, Sergio. 2011. Apresentação Dossiê Pensar com Pierre Clastres. Revista de Antropologia, v. 54, n. 2: 555-556. DOI: https://doi. org/10.11606/2179-0892.ra.2011.39638.

PIEDADE, Acácio Tadeu de Camargo. 1997. Música Yepâ Masa: Por uma Antropologia da Música no Alto Rio Negro.
Florianópolis, dissertação de mestrado, Universidade Federal de Santa Catarina. Disponível em: https://repositorio. ufsc.br/xmlui/handle/123456789/77236. Acesso em 30 de março de 2021.

PIEDADE, Acácio Tadeu de Camargo. 1999. "Flautas e Trompetes Sagrados do Noroeste Amazônico: Sobre Gênero e Música do Jurupari". Horizontes Antropológicos v. 11: 93-118. DOI: https://doi. org/10.1590/S0104-71831999000200005

PIEDADE, Acácio Tadeu de Camargo. 2004. O Canto do Kawoka: Música, Cosmologia e Filosofia entre os Wauja do Alto Xingu. Florianópolis, Tese de doutorado, Universidade Federal de Santa Catarina. Disponível em: https:// repositorio.ufsc.br/handle/123456789/86556 (Acesso em 30 de março de 2021)

PIEDADE, Acácio Tadeu de Camargo. 2011. "From Musical Poetics to Deep Language: The Ritual of the Wauja Sacred Flutes". In HILL, Jonathan D; CHAUMEIL, Jean-Pierre. (eds.) Burst of Breath: New Research on Indigenous Ritual Flutes in Lowland South America. Lincoln, University of Nebraska Press, pp. 239-256.

PRINZ, Ulrike, 2011. "Spirits, Ritual Staging and Transformative Power in the Music of the Upper Xingu River". In Jonathan D; CHAUMEIL, Jean-Pierre. (eds.) Burst of Breath: New Research on Indigenous Ritual Flutes in Lowland South America. Lincoln, University of Nebraska Press. pp. 277-300.

SZTUTMAN, Renato. 2020. "Perspectivismo contra o Estado. Uma política do conceito em busca de um novo conceito de política", Revista de Antropologia v. 63, n. 1: 185-213. DOI: https:// doi.org/10.11606/2179-0892.ra.2020.169177

VALENTINI, Luísa. 2019. Arquivos do futuro: relações, caminhos e cuidados no arranjo preliminar da documentação pessoal de antropólogos. São Paulo,Tese de Doutorado, Universidade de São Paulo. 
artigo | Rafael José de Menezes Bastos | Sobre as flautas sagradas xinguanas e a antropologização do mundo

VIVEIROS DE CASTRO, Eduardo.

1992. "O mármore e a murta: Sobre a inconstância da alma selvagem".

Revista de Antropologia v. 35: 21-74. DOI:

https://doi.org/10.11606/2179-0892.ra

Recebido em 29 de junho de 2020. Aceito em 24 de março de 2021. 